Revista Destaques Acadêmicos, Lajeado, v. 11, n. 3, 2019. ISSN 2176-3070

DOI: http://dx.doi.org/10.22410/issn.2176-3070.v11i3a2019.1963

http://www.univates.br/revistas

\title{
O PEDAGOGO EM HOSPITAIS: COM A PALAVRA GESTORES HOSPITALARES
}

\author{
Ana Maria Costa Barros ${ }^{1}$, Francisca Melo Agapito ${ }^{2}$
}

Resumo: O pedagogo é o profissional que pode atuar em espaços escolares e não escolares. Referente a este último, esse profissional por meio da Pedagogia Hospitalar, pode atuar em classes hospitalares e na brinquedoteca. Nesse sentido, este trabalho teve como objetivo analisar a percepção de gestores sobre a presença e atuação do pedagogo em hospitais públicos e privados no município de Imperatriz/MA. Para tanto se utilizou como aportes teóricos, autores que tratam da temática da pedagogia hospitalar, além de autores que tratam da importância da brinquedoteca para a criança ou adolescente hospitalizado. A presente pesquisa é de cunho qualitativo e descritivo. Como instrumento de coleta de dados, optou-se pela entrevista semiestruturada, realizada com dois gestores de dois hospitais. Os dados foram analisados por meio de análise descritiva. Os resultados obtidos revelaram que os gestores participantes têm consciência da relevância da atuação do pedagogo no ambiente hospitalar. A existência de brinquedotecas nos hospitais pesquisados no município de Imperatriz/ MA é um ponto positivo em prol da criança ou adolescente hospitalizado, contudo, evidenciou-se a ausência de pedagogos nesses espaços. Ratifica-se que o pedagogo é o profissional apto para promover práticas de intervenção que possibilitem à criança e ao adolescente hospitalizado outras vivências promotoras do restabelecimento terapêutico humanizado.

Palavras-chave: Brinquedoteca. Pedagogo Hospitalar. Práticas de intervenção.

\section{INTRODUÇÃO}

A Pedagogia Hospitalar busca a otimização da educação - entendida, aqui, no seu sentido mais amplo - dos enfermos. Acerca do atendimento pedagógico no hospital convém ressaltar que este atendimento pedagógico tem como propósito "[...] desmistificar o ambiente hospitalar, ressignificando suas

1 Graduação em Pedagogia pela Universidade Federal do Maranhão (UFMA).

2 Graduada em Pedagogia (UDESC). Pós Graduação em Metodologia do Ensino Superior (UEMA). Mestra e doutoranda em Ensino (UNIVATES). Professora da Universidade Federal do Maranhão (UFMA). 
práticas e rotinas" e no decorrer desse processo propiciar "[...] a intimidade com o espaço e a confiança naqueles que ali atuam" (FONTES, 2005, p. 122).

Nas palavras de Matos e Mugiatti (2012), a atenção médico-pedagógica à criança hospitalizada não basta por si só, é preciso, também assegurar o ensino escolar contínuo. Nesse sentido, a atuação do pedagogo é imprescindível, visto que este é o profissional que por meio de preparação pode atuar em diferentes setores da sociedade, como é o caso do hospital, nesta ótica, Behrens (1996, p. 45) explica que "A universidade, portanto, torna-se um espaço educativo que busca o desconhecido, o inédito, sem perder de vista o seu projeto pedagógico, político e ideológico". Neste espaço a formação ocorrerá com vistas a dar conta dos avanços e das necessidades da sociedade.

A atuação do pedagogo em ambientes hospitalares visa promover a continuação da escolarização das crianças e adolescentes no hospital. Este irá promover diversas atividades como: utilização de artes, literaturas, projetos culturais e utilização do espaço da brinquedoteca, proporcionando atividades que irão permitir o desenvolvimento cognitivo das crianças e assim elas não ficarão estáticas ou submetidas apenas aos cuidados médicos (MATOS; MUGIATTI, 2012).

Referente à brinquedoteca, cabe ainda destacar que este ambiente visa proporcionar à crianças e adolescentes, acolhimento para que possam diminuir seu stress, angústia por estarem em um ambiente inóspito para eles; através do brincar a criança hospitalizada de alguma forma pode está resgatando sua vida antes da internação assim, portanto o brincar surge como um importante recurso terapêutico, pois permite que os pacientes se socializem bem como enfrentem melhor a doença (MAIA, 2000).

Dado o exposto, este estudo teve como objetivo, analisar a percepção de gestores de dois hospitais do município de Imperatriz/MA sobre a presença e importância da atuação do profissional pedagogo em ambiente hospitalar público e privado. Para tanto, buscou-se entender o que dizem gestores hospitalares acerca desta temática. Este processo foi possível por conta das entrevistas realizadas com os participantes.

\section{ALGUMAS REFLEXÕES SOBRE O PEDAGOGO HOSPITALAR}

No processo de constituição de uma profissão, obter formação é condição indispensável. Assim, a profissionalidade do pedagogo deve trilhar por este caminho e a apropriação de aportes teóricos e práticos deve ser parte desse processo. Este profissional atualmente pode atuar em espaços escolares e não escolares; fator este que representa a propositura de soluções a partir das demandas da contemporaneidade. Conforme aponta Nóvoa (1995, p. 26) "A formação de professores é, provavelmente, a área mais sensível das mudanças em curso no setor educativo: aqui não se formam apenas profissionais; aqui se produz uma profissão". 
A pedagogia se configura hoje como um vasto campo social, atravessando os muros da escola e alcançando os ambientes hospitalares, com o propósito de auxiliar as crianças a continuarem suas atividades educacionais. Nesta lógica, o pedagogo tem um papel salutar neste espaço, devendo seu laboro ser permeado por:

[...] relações afetivas, servindo de reforço para que a criança não desista da luta por saúde e se mantenha esperançosa em sua capacidade de esforço. O professor passa a ser um mediador de estímulos cautelosos, solícito e atento, reinventando formas para desafiar o enfermo quanto à continuidade dos trabalhos escolares, a vencer a doença e a engendrar projetos na vida emancipatória (ORTIZ, 2005, p. 67).

O trabalho do pedagogo no ambiente hospitalar permitirá que a construção de uma ponte entre o hospital e a escola seja concretizada e possa colaborar com a socialização da criança/adolescente. Este irá atuar de forma a promover diversas atividades como: utilização de artes, literaturas, projetos culturais e utilização do espaço da brinquedoteca. Tais atividades podem permitir o desenvolvimento cognitivo das crianças e assim elas nãos ficarão submetidas apenas aos cuidados médicos, além disso, esse tipo de acompanhamento influencia bastante na recuperação das crianças internadas (MATOS, MUGIATTI, 2012).

Nas palavras de Esteves (2008, p. 4) a pedagogia hospitalar é o espaço de integração em que o doente possa estar "[...] dentro de um ambiente acolhedor e humanizado" e manter contato "[...] com seu mundo exterior privilegiando suas relações sociais e familiares". Neste sentido, o pedagogo hospitalar irá atuar de forma a tornar o ambiente mais prazeroso e educativo com a finalidade das crianças e adolescentes encararem da melhor forma o ambiente o qual estão vivendo para que assim eles possam se restabelecer o quanto antes. Matos e Mugiatti (2012, p. 46-47), ressaltam que:

A Pedagogia Hospitalar por suas peculiaridades e características, situa-se numa inter-relação entre os profissionais da equipe de saúde e a educação. Tanto pelos conteúdos da educação formal, como para a saúde e para a vida, como pelo modo de trazer continuidade do processo a que estava inserida de forma diferenciada e transitória a cada enfermo.

A pedagogia hospitalar irá atuar de forma a construir uma ponte entre o hospital e a escola, colaborando com a socialização da criança/adolescente e proporcionado assim uma relação mais próxima com os outros profissionais construindo assim um elo multi e interdisciplinar.

É assegurado por legislações que, hospitais que possuem alas pediátricas tenham brinquedotecas para que enfermos - crianças e adolescentes - possam 
ter momentos prazerosos, brincadeiras, atividades direcionadas para estimular sua cognição, mesmo estando em situação de enfermidade. Conforme a portaria $\mathrm{n}^{\circ} 2.261 / 05$, em seu Artigo $3^{\circ}$ é expresso que a brinquedoteca é:

[...] o espaço provido de brinquedos e jogos educativos, destinado a estimular as crianças e seus acompanhantes a brincar, contribuindo para a construção e/ou fortalecimento das relações de vínculo e afeto entre as crianças e seu meio social (BRASIL, 2005).

A brinquedoteca deve representar um ambiente lúdico em que o faz de conta leve as crianças para um ambiente alegre e feliz, a escolha dos brinquedos deve levar em consideração as diferentes faixas etárias dos pacientes atendidos e o profissional pedagogo deve ter conhecimentos acerca das necessidades dos pacientes para que o atendimento nesse espaço seja eficiente. Logo, para que todos esses processos ocorram de forma eficaz são necessárias condições que possam favorecer a efetivação de tais aspectos, assim:

[...] o professor precisa estar preparado para lidar com as referências subjetivas do aluno, e deve ter destreza e discernimento para atuar com planos e programas abertos, móveis, mutantes, constantemente reorientados pela situação especial e individual de cada criança, ou seja, o aluno da escola hospitalar (FONSECA, 2003, p. 26).

O professor tem um papel fundamental no ambiente hospitalar, pois ele atende pacientes com necessidades educativas transitórias. O profissional irá dar suporte ao desenvolvimento de aprendizagem do aluno dentro do hospital garantindo assim o direito da criança dar continuidade aos seus estudos.

Logo, é necessário um profissional capacitado para atender às necessidades da criança/ adolescente hospitalizada promovendo assim uma educação hospitalar de qualidade que auxilie de forma profícua no processo de ensino aprendizagem.

\section{PROCEDIMENTOS METODOLÓGICOS}

Este estudo é de cunho qualitativo e exploratório. Para Michel (2005, p. 38) em pesquisas qualitativas "[...] a verdade não se comprova numérica ou estatisticamente", mas a pospelo, esta é ratificada "[...] na forma de experimentação empírica, a partir da análise feita detalhadamente, abrangente, consistente e coerentemente, assim como na argumentação lógica das ideias". No que tange o estudo exploratório, convém mencionar que um de seus propósitos reside na exploração do fenômeno resultante da problemática, em prol da apropriação de experiências concernentes ao assunto (TRIVIÑOS, 2008).

O respectivo projeto iniciou em 2015 e estendeu-se até 2017 e buscou, dentre os objetivos propostos, analisar a percepção de gestores da área hospitalar, sobre a presença e importância da atuação do profissional pedagogo 
em ambientes hospitalares públicos e privados no município de Imperatriz/ MA. Neste sentido, participaram desta investigação dois gestores, sendo um de um hospital público e o outro de um hospital privado. O critério utilizado para escolha dos referidos hospitais foi: ter brinquedoteca ou classes hospitalares. Primeiramente foi solicitada a liberação da pesquisa nos hospitais, por meio de declaração de anuência; após, sendo esta autorizada, fez-se o convite aos gestores para participação na pesquisa, mediante apresentação do projeto e assinatura do Termo de Consentimento Livre e Esclarecido (TCLE), garantindo a originalidade, seriedade, além de resguardar os princípios éticos dispostos na Resolução 246/2012.

Para a geração de dados foram realizadas entrevistas semiestruturadas com os participantes da pesquisa. Triviños (2008) afirma que a entrevista semiestruturada, para alguns tipos de pesquisa qualitativa, é um dos principais meios disponíveis para que o investigador obtenha respostas consistentes. No presente trabalho a denominação dos participantes será: G1 e G2 e suas falas estarão aqui destacadas em itálico.

Compreendendo a importância da análise dos resultados, como o caminho para realizar uma reflexão crítica em torno da temática, e consequentemente, abrir espaço para outras pesquisas, nos embasamos nos aportes teóricos abordados nesta pesquisa, como também em outros relevantes para a análise desta pesquisa. Nesta perspectiva, a partir da geração dos dados foi empreendida a análise descritiva; conforme aponta Michel (2005, p. 36) esta "procura conhecer e comparar as várias situações que envolvem o comportamento humano, individual ou em grupos sociais ou organizacionais, nos seus aspectos social, econômico, cultural e etc.". A seguir enfatizam-se as principais falas dos participantes acerca de suas percepções sobre o pedagogo, sua presença e atuação nos hospitais pesquisados.

\section{PEDAGOGOS EM AMBIENTES HOSPITALARES: O QUE PENSAM OS GESTORES}

Assegurado legalmente, o pedagogo é um profissional que está apto a atuar em diferentes espaços em que haja a necessidade de seus conhecimentos pedagógicos. Conforme o artigo $4^{\circ}$ da Resolução CNE/CP N ${ }^{\circ} 1$, de 15 de maio de 2006, que trata das Diretrizes Curriculares para o curso de Pedagogia, em seu parágrafo IV, evidencia a possibilidade do futuro profissional "trabalhar, em espaços escolares e não-escolares, na promoção da aprendizagem de sujeitos em diferentes fases do desenvolvimento humano, em diversos níveis e modalidades do processo educativo" (BRASIL, 2006). Nesta perspectiva, a atuação do pedagogo em ambientes não-escolares, tais como empresas ou hospitais, é assegurada por lei, logo, sobre este último, tanto brinquedotecas como classes hospitalares são espaços de atuação desse profissional. 
Referente à brinquedoteca convém ressaltar que esta é assegurada pela Lei $\mathrm{n}^{\circ} 11.104$, de 21 de março de 2005, que dispõe sobre a obrigatoriedade de instalação de brinquedotecas nas unidades de saúde que ofereçam atendimento pediátrico em regime de internação (BRASIL, 2005), além da Portaria $n^{\circ}$ 2.261/05 que aprova o regulamento que estabelece as diretrizes de instalação e funcionamento das brinquedotecas nas unidades de saúde que ofereçam atendimento pediátrico em regime de internação. A referida portaria ratifica no artigo $\mathrm{V}$, inciso I que:

Os estabelecimentos hospitalares pediátricos deverão disponibilizar brinquedos variados, bem como propiciar atividades com jogos, brinquedos, figuras, leitura e entretenimento nas unidades de internação e tratamento pediátrico como instrumentos de aprendizagem educacional e de estímulos positivos na recuperação da saúde (BRASIL, 2005).

Tomando como base esta premissa, inicialmente identificamos que os hospitais pesquisados estão em conformidade às legislações vigentes, por possuírem brinquedotecas hospitalares para atender os enfermos da ala pediátrica; o hospital público possui este espaço há mais ou menos cinco anos; já o hospital particular iniciou o atendimento aos enfermos em novembro de 2017 e conta com duas brinquedotecas.

Nesta ótica, o foco desta pesquisa direcionou-se à brinquedoteca, assim como a presença e importância da atuação do pedagogo neste espaço, dada sua formação e preparação lhe permitir o laboro neste local. Assim sendo, partindo do entendimento de que a brinquedoteca hospitalar deve ser um ambiente lúdico, que através das brincadeiras, jogos, leituras, dentre outros, vislumbrem possibilitar as crianças hospitalizadas desenvolverem seu intelecto, imaginação, sensibilidade e autoestima (CUNHA, 2007), identificamos as seguintes falas dos participantes sobre este local:

A instalação da brinquedoteca no hospital foi um desejo do gestor da cidade na época, pois não havia na cidade nenhum hospital com essa proposta, a lei 11.104/05 tornava obrigatória a implantação da brinquedoteca em hospitais. Esse espaço existe há mais ou menos cinco anos (G1).

[...] a criação desse espaço foi fundamental para o tratamento e recuperação dos pacientes pediátricos oncológicos, pois os mesmos tinham que se deslocarem para a capital do estado o que influenciava diretamente na recuperação desses eupáticos ${ }^{3}$ (G2).

3 Eupáticos - sinônimo para pacientes. 
Diante do discurso de G1, entendemos que os aspectos legais foram decisivos para a criação da brinquedoteca; conforme a Lei $\mathrm{n}^{\circ} 11.104 / 05$ mencionada na fala de G1 - em seu artigo $1^{\circ}$ determina que "Os hospitais que ofereçam atendimento pediátrico contarão, obrigatoriamente, com brinquedotecas nas suas dependências" e no artigo $3^{\circ}$ que o desrespeito ao artigo exposto acima "[...] configura infração à legislação sanitária federal e sujeita seus infratores às penalidades previstas no inciso II do art. 10 da Lei $\mathrm{n}^{\circ}$ 6.437, de 20 de agosto de 1977" (BRASIL, 2005). De igual modo, a fala de G2, releva a relevância desse espaço para a recuperação de crianças enfermas, como um fator salutar que foi considerado para sua instalação. Nas palavras de Cunha (2007), este espaço é o mais propício para a realização do apoio pedagógico, haja vista os estímulos em prol do desenvolvimento da criança ou adolescente podem ser tornar essenciais para preservar o emocional destes, que, em situação de internação muitas vezes estão fragilizados pela doença.

Para que a brinquedoteca possa ter todos os benefícios que lhe cabem potencializado, ter um profissional qualificado para exercer todas as atividades pertinentes a este espaço é imprescindível, nesta lógica, os participantes da pesquisa foram indagados acerca de suas percepções sobre a relevância da atuação do pedagogo para o exercício nas brinquedotecas ou em classes hospitalares. As falas dos dois participantes foram similares; estes destacaram que o pedagogo é realmente o profissional que deve estar a frente do trabalho desenvolvido nesse espaço. Na visão de Matos de Mugiatti (2012) como um profissional que tem embasamentos teóricos e práticos para possibilitar intervenções direcionadas, o pedagogo, pode contribuir significativamente nos processos cognitivos dos enfermos, além de contribuir para a melhoria da autoestima destes.

Contudo, ao serem questionados sobre a presença do pedagogo nos hospitais que gerem - por ocasião destes terem brinquedoteca hospitalar funcionando, justificando então, a atuação deste profissional - suas falas revelaram a ausência deste profissional. O discurso de G1, - que atua na gestão de um hospital público - denotou que "[...] a ausência de um concurso especifico para os pedagogos atuarem nesse espaço é um dos principais entraves". Já na visão de G2 "o espaço é recente e a demanda de crianças ainda é pequena, assim a presença do pedagogo será um projeto para o ano de 2018".

Apesar de mostrarem compreensão sobre a relevância da atuação do pedagogo no ambiente hospitalar, como evidenciado anteriormente, as falas dos participantes deixam claro que este profissional ainda não tem sua atuação assegurada no respectivo espaço. Acerca do exposto por G1 "[...] a ausência de um concurso", é um ponto fundamental a ser considerado, porém sabemos que na falta de profissional concursado, os seletivos para as áreas necessárias

4 Ressaltamos que a pesquisa foi realizada em novembro de 2017. 
podem ser realizados para minimizar a problemática da falta de profissionais, até que medidas cabíveis sejam tomadas, a exemplo, concurso específico para uma determinada área, nesse caso, o pedagogo hospitalar.

Da mesma forma, não podemos justificar a ausência de um profissional qualificado, pelo quantitativo de crianças ou adolescentes que estão frequentando o espaço. A presença e atuação do trabalho do pedagogo são independentes de quantitativo de demanda, conforme as legislações vigentes, não há nenhum ponto que enfoque o número mínimo para que seja realmente necessário este profissional. Sendo assim, os enfermos que necessitam do espaço da brinquedoteca e utilizam-no, não estão sendo assistidos da forma como prever a legislação, pois o acompanhamento não vem ocorrendo por intermédio de profissional preparado, ou seja, o pedagogo, que conhece como devem ser os procedimentos de mediação pedagógica neste local. Nos dizeres de Fonseca (2003, p. 26) ao se referir à formação e práticas desse profissional, descreve que este deve:

[...] estar preparado para lidar com as referências subjetivas do aluno, e deve ter destreza e discernimento para atuar com planos e programas abertos, móveis, mutantes, constantemente reorientados pela situação especial e individual de cada criança, ou seja, o aluno da escola hospitalar (FONSECA, 2003, p. 26).

O professor tem um papel fundamental no ambiente hospitalar, pois ele atende pacientes com necessidades educativas transitórias. Este, por meio de sua formação poderá dar suporte para elevar a autoestima e o desenvolvimento de aprendizagens do aluno dentro do hospital.

Em suma, as falas dos participantes são homogêneas sobre a importância da atuação desse profissional, contudo a ausência do mesmo indica que são necessárias medidas que promovam sua inserção nesses espaços, visto que existe o local para sua atuação, ou seja, a brinquedoteca, que é um local que permite que os enfermos brinquem, fiquem felizes, distraiam-se e aprendam, mesmo estando internados. Os gestores dos hospitais pesquisados também tem plena consciência e ressaltaram o quanto esses espaços são fundamentais para a recuperação de crianças e adolescentes hospitalizados. Logo, para que este espaço seja torne-se pleno no que tange os procedimentos que lhe cabem e eficaz para o auxílio da criança ou adolescente hospitalizado, a atuação do pedagogo é fundamental.

\section{CONSIDERAÇÕES FINAIS}

A atuação do pedagogo em hospitais é primordial, pois este é o profissional indicado para a realização de processos pedagógicos de crianças hospitalizadas. Seja em classes hospitalares ou na brinquedoteca, o pedagogo irá estabelecer um processo de mediação entre a escola e o hospital (MATOS; 
MUGIATTI, 2012) de forma humanizada, neste período de internação. De acordo com aportes teóricos aqui estudados, ratifica-se o quão relevante é o atendimento à criança hospitalizada por meio do lúdico e de classes hospitalares.

Sendo assim, a criação de brinquedotecas nos hospitais, permite que os pacientes internados tenham seu momento de ludicidade e entretenimento, proporcionando a eles, mesmo que por um curto período de tempo, a elevação da autoestima e a motivação para lutar contra a doença, além de proporcionar construções de conhecimentos. A existência desses espaços configura-se como elemento fundamental para a recuperação desses pacientes hospitalizados. Neste sentido, averiguamos que os hospitais pesquisados no município de Imperatriz/MA estão em consonância com as legislações vigentes, ao terem este espaço terapêutico. Tal assertiva reitera que a atuação de pedagogos nos hospitais é relevante, visto serem estes os profissionais qualificados a atuarem nesses espaços.

A pesquisa revelou ainda, que os gestores dos hospitais têm consciência da importância da atuação dos pedagogos nos ambientes hospitalares. Conforme salientam Matos e Mugiatti (2012), o pedagogo é o profissional com formação aguçada para atuar na realidade que seus saberes são necessários; por meio de fundamentação teórica e conhecimentos pedagógicos estes podem proporcionar uma ação coerente e consistente que possibilitará resultados eficazes em seus alunos. No entanto, a ausência destes profissionais nos espaços das brinquedotecas hospitalares comprovou que ainda são necessárias medidas que venham a garantir a sua atuação em tais ambientes, configurandose uma situação emergencial, pois legalmente esta situação é assegurada, embora, efetivamente isto ainda não aconteça. Assim, espera-se que os gestores contratem pedagogos atuar nos espaços da brinquedoteca e, que este trabalho possa promover reflexões e debates acerca da relevância do tema e da emergência da atuação do pedagogo em ambiente hospitalar.

\section{REFERÊNCIAS}

BEHRENS, Marilda Aparecida. Formação continuada dos professores e a prática pedagógica. Curitiba: Champagnat, 1996.

BRASIL. Presidência da República - Casa Civil. Legislação. Lei n 11.104, de 21 de março de 2005. Disponível em:< http://www.planalto.gov.br/ccivil_03/_Ato20042006/2005/Lei/L11104.htm>. Acesso em 28/10/2017 às 18:00 h.

. Ministério da Saúde - Gabinete do Ministro. Portaria n 2.261, de 23 de

novembro de 2005. Aprova o Regulamento que estabelece as diretrizes de instalação e funcionamento das brinquedotecas nas unidades de saúde que ofereçam atendimento pediátrico em regime de internação. Disponível em: <http://bvsms.saude.gov.br/ bvs/saudelegis/gm/2005/prt2261_23_11_2005.html> Acesso em: 24 de novembro às 22:30h. 
Resolução CNE/CP Nº1/ 2006. Diretrizes curriculares nacionais para o curso de graduação em pedagogia, licenciatura. Disponível em:< http://portal.mec.gov.br/ cne/arquivos/pdf/rcp01_06.pdf>. Acesso em 23 de novembro de 2017 às 16:30 h.

CUNHA, Nylse Helena Silva. Brinquedoteca: definição, histórico no Brasil e no mundo. In: $O$ direito de brincar: a brinquedoteca. Adriana Friedmann. São Paulo: Scritta: ABRINQ. 2007.

ESTEVES, Cláudia Regina. Pedagogia hospitalar: um breve histórico. 2008. Disponível em: <http:/ / docplayer.com.br/6547581-Pedagogia-hospitalar-a-imtancia-do-apoiopedagogico-dentro-dos-hospitais-para-jovens-e-criancas.html>. Acesso em: 20 de novembro de 2016 às 18:15 hs.

FONSECA, Eneida Simões da. Atendimento escolar no ambiente hospitalar. São Paulo: Memnon, 2003.

FONTES, Rejane de Sousa. A escuta pedagógica a criança hospitalizada: discutindo o papel da educação no hospital. Revista Brasileira de Educação, n.29, p.119-138, 2005.

MAIA, Célia Isabel Bento (Org). Brinquedoteca hospitalar Shishiro Otake. In: SANTOS, Santa Marli Pires dos. Brinquedoteca, a criança, o adulto e o lúdico. Petrópolis: Vozes, 2000.

Pedagogia Hospitalar: A humanização integrando educação e saúde. 6 ed. Petrópolis, RJ: Vozes, 2012.

MICHEL, Maria Helena. Metodologia e pesquisa científica em ciências sociais. São Paulo: ATLAS, 2005.

NÓVOA, Antônio. O passado e o presente dos professores. IN: NÓVOA, A. (Coord.). Profissão professor. Porto: Editora Porto, 1995.

ORTIZ, Leodi Conceição; FREITAS, Soraia Napoleão. Classe Hospitalar - caminhos pedagógicos entre saúde e educação. $1^{a}$ Edição. Santa Maria. Ed. UFSM. 2005.

TRIVIÑOS, Augusto Nibaldo Silva. Introdução à Pesquisa em Ciências Sociais: a pesquisa qualitativa em educação. São Paulo: Atlas, 2008. 